\title{
Molecular Diagnostics in Pulmonary Infections
}

\author{
Catherine A. Gao, John C. Huston, \\ Patricia Valda Toro, Samir Gautam, \\ and Charles S. Dela Cruz
}

\section{Molecular Diagnostics- Recognition and Identification of the Pathogen}

\section{Illustrative Case (See Fig. 12.1)}

A 45-year-old actively smoking male presents to the emergency department with a 3-day history of high fevers, cough productive of greenish sputum, and shortness of breath (SOB). In the emergency department, he is found to be hypoxemic and a portable chest $\mathrm{X}$-ray shows a right lower lobe opacity read as infiltrate versus atelectasis. $\mathrm{He}$ is started on ceftriaxone and doxycycline per community-acquired pneumonia (CAP) guidelines and admitted to the medicine service. Five days into the hospitalization, the patient decompensates and ultimately requires intubation for

These two authors contributed equally to this work and therefore the author list can be cited with either JH or CG as first author hypoxemic respiratory failure. Blood and sputum cultures are unrevealing. Urinary antigens for Streptococcus pneumoniae and Legionella pneumophila are negative. While in the intensive care unit, the patient continues to spike fevers. Blood cultures are obtained again but remain negative. The antimicrobial coverage is broadened to vancomycin and piperacillin-tazobactam. Eventually, the patient is extubated and transferred back to the general medical floor. He is eventually narrowed to amoxicillin/clavulanate. $\mathrm{He}$ is discharged to a short-term rehabilitation facility still requiring two liters of oxygen.

\section{The Traditional Approach to Diagnosing Pneumonia: History, Physical Exam, and Basic Diagnostics}

Confirming or refuting a suspected diagnosis of pneumonia has long depended on history-taking, physical examination, general laboratory studies,

\footnotetext{
S. Gautam

Yale School of Medicine, Department of Internal Medicine, Section of Pulmonary, Critical Care, and Sleep Medicine, New Haven, CT, USA e-mail: samir.gautam@yale.edu

C. S. Dela Cruz $(\bowtie)$

Yale School of Medicine, Department of Internal Medicine, Section of Pulmonary, Critical Care, and Sleep Medicine and Department of Microbial Pathogenesis, New Haven, CT, USA e-mail: charles.delacruz@yale.edu
} 


\section{Current Workup of Pneumonia}

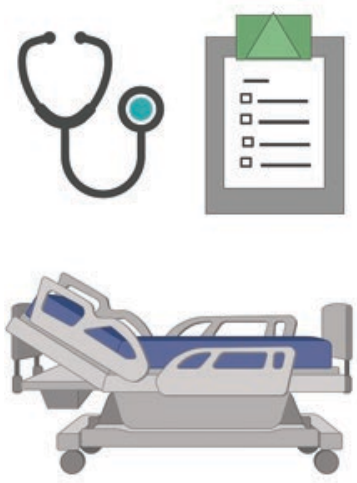

History and Physical

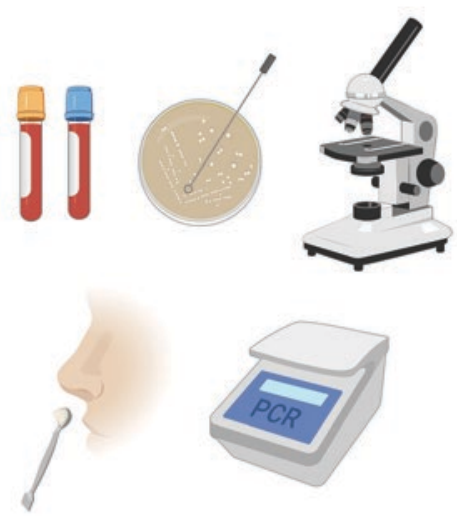

Blood/Sputum Cultures and Nasopharyngeal Viral Testing

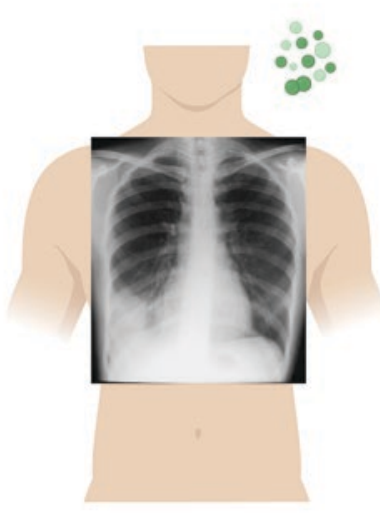

Chest X-ray

Fig. 12.1 Current approach to the workup of suspected pneumonia. This approach includes obtaining a careful clinical history and physical exam, sputum and blood cultures, and chest X-ray

and basic radiologic studies including chest $\mathrm{X}$-ray. A dichotomous approach aimed at defining both host and pathogen is generally taken. Important host-defining historical features include any degree of immunosuppression (e.g., neutropenia, chronic corticosteroid use, malignancy, liver or kidney disease, diabetes mellitus, immunosenescence), underlying structural lung disease (e.g., obstructive lung diseases, bronchiectasis), risk of aspiration (due to altered sensorium, bulbar muscle weakness, dysphagia, esophageal disorders), and relevant exposures (i.e., travel, sick contacts, animals). Regarding the pathogen, one probes the clinical history for susceptibilities and characteristic syndromesfor example, a background of chronic alcoholism or poorly treated HIV will point to aspiration pneumonia and opportunistic infections, respectively. The patient's clinical course is also closely observed in-house for clues to an etiology, for example, rapid response to empiric antibiotics indicating infection.

While these historical subtleties will provide important guidance for the seasoned, sophisticated clinician, simpler heuristics more often determine diagnostic decision-making. In the case of pneumonia, the basic defining features include a radiographic infiltrate, systemic signs of infection (e.g., fever), and pulmonary symptoms of infection (e.g., productive cough, SOB, and occasionally pleuritic chest pain) [4]. Unfortunately, in practice, these historical features may be insufficient and potentially misleading as they may manifest in completely different disease processes, many of which do not require antibiotics. These include decompensated heart failure (SOB), pulmonary embolism (pleuritic chest pain), COPD exacerbation (SOB and cough), and even allergic rhinitis (fatigue, malaise, productive cough). Furthermore, studies have shown that history has poor interobserver reliability in the ability to record symptoms in patients with suspected pneumonia. For instance, the classic amalgam of fever, cough, tachycardia, and crackles has a sensitivity of less than $50 \%$ for the diagnosis of acute pneumonia, and no other constellation of historical and physical findings has performed better [5].

For the most part, microbiological diagnosis of bacterial pneumonia has remained unchanged since the 1800 s, as we continue to rely on traditional sputum gram stain and culture. Its longev- 
ity, however, belies its relatively dismal diagnostic performance. This was starkly illustrated by a landmark study in 2015, which showed that in more than $60 \%$ of the cases, no bacterial or viral organism could be identified [6]. Equally poor results are seen in patients with ventilatorassociated pneumonia, in whom only $50 \%$ of pathogens are identified [7]. In addition to poor sensitivity, traditional culture suffers from slow turn-around time, as they take on average 36-48 hours to result [8].

Chest radiography has long been considered essential in the diagnosis of pneumonia. However, the sensitivity of chest radiography for pneumonia is less than $50 \%$, and the positive predictive value is only $30 \%$ [9]. Furthermore, chest X-rays are of variable quality and often difficult to interpret due to underlying cardiopulmonary disease, obesity, etc. Finally, initial studies may be falsely negative, due to a phenomenon known as "blos- soming infiltrate," which has been observed in up to $7 \%$ of patients in one study [10].

Given these many shortcomings of traditional diagnostics for pneumonia, the development of advanced tools is clearly needed. Excitingly, novel ways to diagnose pneumonia are rapidly emerging, with some already folded into practice. This section will cover these newer techniques, which run the technological gamut from protein biomarkers to whole genome sequencing and proteomic profiling.

\section{Pathogen-Associated Biomarkers (See Table 12.1 for Summary)}

An important component of the diagnostic armamentarium in pneumonia is a family of assays aimed at detecting bacterial antigens in bodily fluids (e.g., serum and urine). This approach is

Table 12.1 Summary of pathogen diagnostics

\begin{tabular}{|c|c|c|c|c|c|}
\hline Test name & Test description & $\begin{array}{l}\text { Sensitivity and } \\
\text { specificity, } \\
\text { approximate }\end{array}$ & Advantages and disadvantages & Availability & $\begin{array}{l}\text { Selected } \\
\text { references }\end{array}$ \\
\hline \multicolumn{6}{|c|}{ Genomic profiling of pathogen } \\
\hline RT- PCR & $\begin{array}{l}\text { Real-time } \\
\text { polymerase chain } \\
\text { reaction to } \\
\text { identify and } \\
\text { quantify pathogen }\end{array}$ & $\begin{array}{l}\text { Sensitivity } \\
90 \% \\
\text { Specificity } \\
100 \%\end{array}$ & $\begin{array}{l}\text { + Simple and fast } \\
\text { + Can quantify pathogen load } \\
\text { + Allows identification of } \\
\text { resistance genes } \\
\text { - Inadequate sensitivity for } \\
\text { lower respiratory samples }\end{array}$ & $\begin{array}{l}\text { Commercially } \\
\text { available }\end{array}$ & $\begin{array}{l}{[3,} \\
11-13]\end{array}$ \\
\hline $\begin{array}{l}\text { Nucleic acid } \\
\text { amplification } \\
\text { test }\end{array}$ & $\begin{array}{l}\text { Amplification of } \\
\text { specific nucleic } \\
\text { acids sequences } \\
\text { followed by } \\
\text { hybridization of } \\
\text { probe }\end{array}$ & & $\begin{array}{l}\text { + Fast diagnosis of TB } \\
\text { ( } 24-48 \text { hours) } \\
\text { + More sensitive than AFB } \\
\text { smear } \\
\text { + Works with low } \\
\text { concentration samples } \\
\text { + Fast test of drug resistance } \\
\text { with high sensitivity and } \\
\text { specificity } \\
\text { - Less sensitive than culture }\end{array}$ & & $\begin{array}{l}{[19-25,} \\
30]\end{array}$ \\
\hline $\begin{array}{l}\text { Multiplex } \\
\text { PCR }\end{array}$ & $\begin{array}{l}\text { Amplification of } \\
\text { many nucleic acid } \\
\text { targets within one } \\
\text { reaction }\end{array}$ & & $\begin{array}{l}\text { + Allows diagnosis of } \\
\text { multiple pathogens at once } \\
\text { + Can quantify viral load } \\
\text { - Lower sensitivity due to } \\
\text { primer-primer interaction } \\
\text { - May detect viruses not } \\
\text { related to pathogenic process. }\end{array}$ & $\begin{array}{l}\text { Commercially } \\
\text { available }\end{array}$ & $\begin{array}{l}{[13,15,} \\
19,27]\end{array}$ \\
\hline
\end{tabular}


Table 12.1 (continued)

\begin{tabular}{|c|c|c|c|c|c|}
\hline Test name & Test description & $\begin{array}{l}\text { Sensitivity and } \\
\text { specificity, } \\
\text { approximate }\end{array}$ & Advantages and disadvantages & Availability & $\begin{array}{l}\text { Selected } \\
\text { references }\end{array}$ \\
\hline $\begin{array}{l}\text { MALDI-TOF } \\
\text { MS }\end{array}$ & $\begin{array}{l}\text { Mass } \\
\text { spectrometry to } \\
\text { identify bacterial } \\
\text { organisms by their } \\
\text { proteomic profile }\end{array}$ & & $\begin{array}{l}\text { + Fast (minutes) } \\
\text { + Low-cost per sample } \\
\text { + Detects antibiotic resistance }\end{array}$ & & [32-34] \\
\hline $\begin{array}{l}\text { Volatile } \\
\text { organic } \\
\text { compounds } \\
\text { (VOCs) }\end{array}$ & $\begin{array}{l}\text { Mass } \\
\text { spectrometry to } \\
\text { analyze VOCs in } \\
\text { exhaled breath } \\
\text { and diagnose } \\
\text { pneumonia }\end{array}$ & $\begin{array}{l}\text { Sensitivity } \\
75 \% \\
\text { Specificity } \\
73 \%\end{array}$ & + Noninvasive & & {$[35-36]$} \\
\hline \multicolumn{6}{|c|}{ Metataxonomics and metagenomics } \\
\hline $\begin{array}{l}\text { 16S rRNA } \\
\text { sequencing }\end{array}$ & $\begin{array}{l}\text { Specific bacterial } \\
\text { taxa are } \\
\text { sequenced used } \\
\text { primers to } \\
\text { epitopes of highly } \\
\text { conserved } \\
\text { sequences of } \\
\text { ribosomal RNA }\end{array}$ & & $\begin{array}{l}\text { + Rapid identification of } \\
\text { bacterial species } \\
\text { + Provides quantification of } \\
\text { pathogen abundance } \\
\text { + Low-cost per sample } \\
\text { - Resistance and virulence } \\
\text { genes are not detected } \\
\text { - Requires bronchial sample }\end{array}$ & & [37-38] \\
\hline $\begin{array}{l}\text { Whole } \\
\text { genome } \\
\text { sequencing } \\
\text { (WGS) }\end{array}$ & $\begin{array}{l}\text { Wide net } \\
\text { sequencing of } \\
\text { sample }\end{array}$ & & $\begin{array}{l}\text { + Includes resistance, } \\
\text { virulence, and antimicrobial } \\
\text { susceptibilities } \\
\text { + Rapid detection of TB and } \\
\text { drug resistance } \\
\text { + Identification of mixed } \\
\text { strains can help optimize } \\
\text { therapies } \\
\text { + Allows study of } \\
\text { transmission patterns } \\
\text { - May sequence colonizing } \\
\text { nonpathogenic organism }\end{array}$ & & [40-46] \\
\hline
\end{tabular}

already in widespread practice given its relatively low cost, high specificity, rapid processing times, and ready accessibility to samples. The principal disadvantage derives from the indirect detection of pathogen through an antigen rather than isolation of the organism, which is necessary for assessing antibiotic susceptibility $[11,12]$.

A common example is the assay for S. pneumoniae urinary antigen (the C-polysaccharide), which has a sensitivity and specificity of $72 \%$ and $96 \%$, respectively, in patients with non-bacteremic pneumonia. Importantly, initiation of antibiotics does not impair test characteristics, as antigens remaining positive for at least 3 days after receiving appropriate therapy [13]. Another example is the urine immunoassay for detecting Legionella pneu- mophilia serogroup 1, which causes between 50\% and $70 \%$ of Legionella infections. This test has $80 \%$ sensitivity and greater than $99 \%$ specificity [14].

\section{Genomic Profiling of Pathogen}

\section{Multiplex PCR}

Polymerase Chain Reaction (RT-PCR) is a simple and rapid means of identifying bacterial and viral pathogens in the blood, sputum, and bronchoalveolar lavage (BAL) fluid in order identify causative organisms of pneumonia. Turnaround is typically on the scale of just a few hours.

Multiplex PCR allows for amplification of many nucleic acid targets within one reaction 
[15], potentially enabling diagnosis of multiple pathogens simultaneously. There are numerous commercial multiplex PCR systems currently in use to diagnose pneumonia-mostly viral infection from nasopharyngeal sampling, but some bacterial pathogens as well. A downside to multiplex PCR is the potential for primer-primer interactions, which can interfere with amplification and decrease the sensitivity of the test; bead-array and microarrays are used to combat this issue [15]. A second issue is the risk of false positivity, which can stem either from the exquisite sensitivity of the test or from coincidental detection of organisms that are potentially pathogenic, but not producing disease in a given patient.

Multiplex PCR has changed our basic understanding of what causes pneumonia; in a landmark trial by the EPIC team, among more than 2000 patients with radiographic evidence of pneumonia, the majority of cases with a confirmed microbiological etiology were viral, and the most frequent pathogen was rhinovirus, accounting for $9 \%$ of cases $[6,16]$. It should be noted, however, that the sampling site in this study was the nasopharynx, and therefore the recovered virus may simply represent a bystander and not the pathogen responsible for the lower respiratory tract infection (LRTI). Further complicating the interpretation of viral studies is that $15 \%$ of healthy individuals carry a respiratory tract pathogen at any given time [16].

\section{Quantitative PCR}

Recent studies have highlighted the prognostic importance of assessing pathogen load, which is enabled by real-time PCR (RT-PCR). For example, confirming an elevated $S$. pneumoniae DNA in the serum of patients with confirmed CAP was associated with a higher mortality, need for mechanical ventilation, and risk of shock [17]. Other studies have demonstrated a dose-dependent relationship, with higher bacterial DNA loads correlating with more severe disease [18].

\section{PCR for Recognition of Genes Mediating Resistance or Virulence}

In addition to defining the presence and quantity of pathogen, PCR can be used to identify genetic resistance determinants. The quintessential exam- ple is identification of the mecA gene, which confers methicillin resistance to Staphylococcus aureus species, that is, methicillin-resistant $S$. aureus (MRSA). Specifically, the gene encodes for penicillin-binding protein $2 \mathrm{a}$, which has a decreased affinity for beta-lactam antibiotics that renders almost the entire drug class obsolete, with the exception of late-generation cephalosporins $[19,20]$. Multiple iterations of tests aimed at identifying MRSA have culminated in an effective multiplex assay that recognizes four pertinent genes in only 2-6 hours [21]. These include the SCCmec-orfX junction (which indicates the Staphylococcus genus), spa (which specifies $S$. aureus), mecA (the resistance gene), and mecC (a mecA homolog). Additional MRSA assays have been developed; as a class, they perform well with sensitivities greater than $90 \%$ and specificities approaching $100 \%$ [19].

PCR tests for virulence factors in common bacterial LRTI pathogens such as $S$. pneumoniae and Moraxella catarrhalis have been tested, but with mixed success, mainly due to the frequent colonization of these organisms in the upper respiratory tract [22]. For example, tests for the pneumolysin gene (a highly cytotoxic and inflammatory virulence factor for $S$. pneumoniae) in lower respiratory samples have shown inadequate sensitivity and specificity, and therefore have not been adopted into clinical practice [23].

\section{PCR for Detection of Mycobacteria}

An area of increasing interest is the rapid diagnosis of active Mycobacterium tuberculosis (MTb) infection. For decades, clinicians have relied on sputum acid-fast bacilli smears and culture, which have numerous drawbacks. First, the turnaround time is quite long - often taking months to result, resulting in delayed initiation of antimicrobials, and prolonged isolation of suspected patients. Second, sensitivity is quite poor, with detection rates estimated at $45-80 \%[24,25]$. Consequently, invasive testing may be necessary to make the diagnosis, including bronchoscopy and biopsy.

To address these issues, PCR assays are now being used in clinical practice. This technology can help diagnose pulmonary TB in 24-48 hours [26], and it has further utility in distinguishing between $\mathrm{MTb}$ and non-tuberculous mycobacteria on positive 
AFB smears, with a positive predictive value of over $95 \%$. Although still less sensitive than culture, the PCR test can detect MTb at a concentration of 1-10 organisms per milliliter [27-29]. This feature enables detection of MTb in patients with a negative AFB smear, with approximate 50-80\% accuracy [30]. PCR tests can also detect resistance against drugs including rifampin or isoniazid with high sensitivity and specificity, can be completed in only 2 hours, and are highly sensitive and specific [31].

\section{Mass Spectrometry for Proteomic Profiling}

\section{MALDI-TOF MS}

Matrix-assisted laser desorption ionization time of flight mass spectrometry (MALDI-TOF MS) is a technique with the capacity to identify pathogens through recognition of unique proteomic profiles [32]. In contrast to traditional cultures, which take 36-48 hours to result, MALDI-TOF MS takes minutes, with a relatively low cost per sample [33]. In addition to pathogen identification, this methodology can also detect antibiotic resistance, for instance through recognition of specific proteins such as PBP2a in S. aureus, which indicates MRSA [34].

\section{Volatile Organic Compounds}

Another use of mass spectrometry is in the characterization of volatile organic compounds (VOCs) so-called "breathomics," which has been hailed as a promising noninvasive method of sampling the respiratory tract [35]. Exhaled air contains numerous VOCs, including metabolites related to both host and pathogen. Select VOCs have been shown to be associated with pneumonia. As an example, one study identified 12 compounds that could correctly diagnose VAP with a sensitivity and specificity of $75 \%$ and $73 \%$ respectively [36], but concerns have been raised regarding the risk of bias in this and other early investigations.

\section{Metataxonomics and Metagenomics}

Whole genome sequencing (WGS) and $16 \mathrm{~S}$ rRNA gene sequencing are high-output tech- niques that aim to comprehensively characterize the respiratory microbiome in a high-throughput manner.

$16 \mathrm{~S}$ rRNA sequencing depends on the use of nucleic acid primers against highly conserved sequences of ribosomal RNA. This allows identification of a bacterial species and some quantitative data on the relative abundance of the pathogen. Although rapid and relatively low in cost (per sample), it lacks the ability to detect genetic material outside of the ribosome, leaving resistance and virulence genes unrecognized.

A study using 16S rRNA sequencing on bronchial aspirates of mechanically ventilated patients with suspected VAP showed promising results. Compared to traditional bronchial aspirate cultures, 16S rRNA sequencing matched the culture result in $85 \%$ of cases, but time to identification was significantly shorter in the $16 \mathrm{~S}$ group [37, 38], which is meaningful since early antibiotics (within 48 hours) are known to reduce mortality in patients with VAP [39].

Contrary to $16 \mathrm{~S}$, WGS fully sequences the respiratory microbiome, and as such can report on the presence of resistance and virulence genes [40, 41]. As discussed above, PCR-based assays have the capability to identify MTb and rifampin resistance in just 2 hours, but mutations outside of the probed sequence are not identified. WGS allows recognition of these, although the relative significance of such mutations may not be known $[42,43]$. With time, this issue should be addressed with genome-wide association studies (GWAS), which aim to delineate a catalog of resistance loci [48-50]. This will serve as a reference for clinical samples and may help in creating models that predict future resistance to antimicrobials.

The granularity that WGS provides can also be used to trace transmission patterns of infection. This idea was exploited to track an outbreak of Human Adenovirus-7 (HAdV-7) causing ARDS at military training bases in Hubei Province, China. WGS helped identify a "super-spreader" who was not quarantined and had prolonged viral shedding [46]. Additionally, WGS can offer basic insight into the dysbiosis that often accompanies lung diseases such as chronic obstructive pulmonary disease (COPD). This is exemplified by a study examining 
rhinovirus-induced exacerbation, which demonstrated a significant rise in the overall bacterial burden [47].

One of the recognized weaknesses of WGS is target specificity. Though advanced post hoc processing methods allow for elimination of host genetic signal, there is no way to identify colonizing nonpathogenic or commensal organisms [44]. Additional disadvantages of meta-omics in general include the risk of contamination, inability to discriminate live from dead microbial DNA, and cost.

\section{Molecular Diagnostics- Characterizing the Host Response}

\section{Host Response Biomarkers (See Table 12.2 for Summary)}

In general, clinicians are alerted to infection by the host's inflammatory response to the pathogen. Observable manifestations of lung inflammation include classic systemic signs such as fever, local symptoms such as cough and purulent sputum, and radiographic evidence of neu-

Table 12.2 Summary of host response diagnostics

\begin{tabular}{|c|c|c|c|c|c|}
\hline Test name & Test description & $\begin{array}{l}\text { Sensitivity, } \\
\text { specificity, odds } \\
\text { ratio, hazard ratios, } \\
\text { area under curve }\end{array}$ & Advantages, disadvantages & Availability & $\begin{array}{l}\text { Selected } \\
\text { references }\end{array}$ \\
\hline $\begin{array}{l}\text { C-reactive } \\
\text { protein }(\mathrm{CRP})\end{array}$ & $\begin{array}{l}\text { Early acute } \\
\text { phase reactant } \\
\text { synthesized in } \\
\text { response to IL-6 }\end{array}$ & $\begin{array}{l}\text { Sensitivity: } 60 \% \\
\text { Specificity } 83 \%\end{array}$ & $\begin{array}{l}\text { + Highly sensitive, } \\
\text { elevated in Legionella as } \\
\text { opposed to other } \\
\text { biomarkers } \\
\text { + Widely available, } \\
\text { validated as point of care } \\
\text { lab test } \\
\text { - Nonspecific }\end{array}$ & $\begin{array}{l}\text { Widespread; } \\
\text { also available } \\
\text { as point of care } \\
\text { test }\end{array}$ & [51-55] \\
\hline Procalcitonin & $\begin{array}{l}\text { Prohormone of } \\
\text { calcitonin; } \\
\text { Elevates in } \\
\text { response to } \\
\text { PAMPs, } \\
\text { DAMPs; } \\
\text { Suppressed by } \\
\text { type I IFN } \\
\text { generated during } \\
\text { viral infection }\end{array}$ & $\begin{array}{l}\text { Sensitivity ranges } \\
\text { from multiple } \\
\text { studies: Averages } \\
\text { approximately } \\
74-87 \% \\
\text { Specificity } \\
\text { approximately } \\
\text { through numerous } \\
\text { studies: } 60-90 \%\end{array}$ & $\begin{array}{l}\text { + Relatively widespread } \\
\text { + More sensitive and } \\
\text { specific in identifying } \\
\text { bacterial infections } \\
\text { + Not much affected by } \\
\text { use of steroids } \\
\text { + Validated in pneumonia, } \\
\text { sepsis, shock } \\
\text { + Beneficial in } \\
\text { antimicrobial stewardship } \\
\text { programs } \\
\text { - Conflicting data (though } \\
\text { mostly positive) in } \\
\text { antibiotic algorithms } \\
\text { - Elevated in renal } \\
\text { disease and some } \\
\text { non-specificity }\end{array}$ & $\begin{array}{l}\text { Widespread } \\
\text { and commonly } \\
\text { available }\end{array}$ & [56-70] \\
\hline $\begin{array}{l}\text { Inflammatory } \\
\text { cytokines } \\
\text { (IL-6, IL-8, } \\
\text { IL-10, among } \\
\text { others) }\end{array}$ & $\begin{array}{l}\text { Elevated in acute } \\
\text { setting through a } \\
\text { variety of } \\
\text { pathways }\end{array}$ & $\begin{array}{l}\text { Elevated levels of } \\
\text { IL-6 and Il-10 } \\
\text { correspond with } \\
\text { risk of death with } \\
\text { hazard ratio } 20.5\end{array}$ & $\begin{array}{l}\text { + Shown to predict } \\
\text { mortality in hospitalized } \\
\text { patients with CAP } \\
+ \text { Strong association with } \\
\text { disease severity } \\
\text { - Rapid rise/fall, on the } \\
\text { order of hours }\end{array}$ & $\begin{array}{l}\text { Available as } \\
\text { send-out test } \\
\text { but not } \\
\text { commonly } \\
\text { used in clinical } \\
\text { care }\end{array}$ & [71-74] \\
\hline
\end{tabular}


Table 12.2 (continued)

\begin{tabular}{|c|c|c|c|c|c|}
\hline Test name & Test description & $\begin{array}{l}\text { Sensitivity, } \\
\text { specificity, odds } \\
\text { ratio, hazard ratios, } \\
\text { area under curve }\end{array}$ & Advantages, disadvantages & Availability & $\begin{array}{l}\text { Selected } \\
\text { references }\end{array}$ \\
\hline $\begin{array}{l}\text { Mid-regional } \\
\text { pro- } \\
\text { adrenomedullin } \\
\text { (MR-proADM) }\end{array}$ & $\begin{array}{l}\text { A member of the } \\
\text { calcitonin } \\
\text { peptide family, } \\
\text { widely } \\
\text { synthesized and } \\
\text { elevated in acute } \\
\text { infection }\end{array}$ & $\begin{array}{l}\text { Sensitivity: } \\
67-92 \% \\
\text { Specificity: } \\
66-85 \%\end{array}$ & $\begin{array}{l}\text { + Some studies have } \\
\text { shown it to be superior } \\
\text { compared with } \\
\text { procalcitonin } \\
\text { - Still not routinely used } \\
\text { in clinical practice; not as } \\
\text { much data as classic } \\
\text { biomarkers }\end{array}$ & $\begin{array}{l}\text { Not widely } \\
\text { available yet }\end{array}$ & {$[81-82]$} \\
\hline $\begin{array}{l}\text { Pro- } \\
\text { vasopressin } \\
\text { (pro-VNP) } \\
\text { Also called } \\
\text { "copeptin" for } \\
\text { C-terminal } \\
\text { pro- } \\
\text { vasopressin }\end{array}$ & $\begin{array}{l}\text { Precursor to } \\
\text { vasopressin, } \\
\text { marker of stress, } \\
\text { and fluid balance }\end{array}$ & $\begin{array}{l}\text { Sensitivity } 70 \% \\
\text { Specificity } 85 \%\end{array}$ & $\begin{array}{l}\text { + Promising data } \\
\text { - Still not routinely used } \\
\text { in clinical practice; not as } \\
\text { much data as classic } \\
\text { biomarkers }\end{array}$ & $\begin{array}{l}\text { Not widely } \\
\text { available yet }\end{array}$ & [79-80] \\
\hline $\begin{array}{l}\text { (Mid-regional) } \\
\text { Pro-atrial } \\
\text { natriuretic } \\
\text { peptide } \\
\text { (pro-ANP) }\end{array}$ & $\begin{array}{l}\text { Family of } \\
\text { natriuretic } \\
\text { peptides, } \\
\text { established for } \\
\text { congestive heart } \\
\text { disease but also } \\
\text { elevated in high } \\
\text { cardiac output, } \\
\text { sympathetic } \\
\text { stimulation, } \\
\text { metabolism }\end{array}$ & $\begin{array}{l}\text { To predict } \\
\text { short-term death: } \\
\text { sensitivity of } 91 \% \text {, } \\
\text { specificity of } 62 \% \text {, } \\
\text { positive predictive } \\
\text { value of } 10 \%, \text { and } \\
\text { negative predictive } \\
\text { value of } 99 \%\end{array}$ & $\begin{array}{l}\text { + Promising data } \\
\text { - Still not routinely used } \\
\text { in clinical practice; not as } \\
\text { much data as classic } \\
\text { biomarkers }\end{array}$ & $\begin{array}{l}\text { Not widely } \\
\text { available yet }\end{array}$ & $\begin{array}{l}{[77,} \\
108]\end{array}$ \\
\hline $\begin{array}{l}\text { Alveolar } \\
\text { pentraxin } 3 \\
\text { (PTX3) }\end{array}$ & $\begin{array}{l}\text { An acute-phase } \\
\text { mediator } \\
\text { produced by } \\
\text { lung cells }\end{array}$ & $\begin{array}{l}\text { PTX3 levels } \\
\geq 1 \mathrm{ng} / \mathrm{ml} \text { in BAL } \\
\text { fluid predicted } \\
\text { pneumonia with } \\
\text { sensitivity }(92 \%), \\
\text { specificity }(60 \%), \\
\text { and negative } \\
\text { predictive value } \\
(95 \%)\end{array}$ & $\begin{array}{l}\text { + Direct source-studied } \\
\text { in BAL } \\
\text { - Invasive sampling } \\
\text { method }\end{array}$ & $\begin{array}{l}\text { Not widely } \\
\text { available yet }\end{array}$ & [84] \\
\hline
\end{tabular}

trophilic infiltrates. Inflammatory diagnostics have progressed immensely from simple leukocyte counts to serum biomarkers, such as C-reactive protein and procalcitonin, and more recently a wave of new biomarkers and genomic techniques. The sensitivity and specificity of these newer techniques vastly outstrips that of traditional pneumonia diagnostics; their implementation in clinical practice promises to improve not only diagnosis of infection, but also prediction of deterioration and tapering of therapy. These improvements should help to limit antibiotic overuse-one of the major unsolved problems in pneumonia.

\section{C-reactive Protein}

C-reactive protein (CRP) is an early acute phase reactant that is synthesized in the liver in response to IL-6 secreted by monocytes and macrophages. The " $C$ " in its name derives from its reaction with the C-polysaccharide of $S$. pneumoniae as the first biomarker for pneumococcal pneumonia 
$[51,52]$. It is highly sensitive, but rather nonspecific as the level rises in most inflammatory conditions, and therefore must be used judiciously in the context of bacterial pneumonia. Interestingly, it is especially elevated in cases of Legionella infection compared with other biomarkers [53]. Given its widespread availability, it has been validated as a point-of-care (POC) lab test to guide antibiotic use in primary care [54], and levels have been correlated to disease severity and complications in community-acquired pneumonia [55]. Used with other inflammatory marker profiles, CRP may be used to pinpoint the time of infection: In patients who present within 3 days of disease onset, CRP was low, but in patients who present after more than 3 days of symptom onset, CRP levels rose significantly [56].

\section{Procalcitonin}

Procalcitonin is the prohormone of calcitonin, which is expressed mostly in the C-cells of the thyroid during health. In response to pathogenassociated molecular patterns (PAMPs), damageassociated molecular patterns (DAMPs), and inflammatory cytokines during infection, however, the expression of procalcitonin is upregulated in virtually every tissue and cell type [57]. Importantly, its expression is suppressed by type I interferons generated during viral infection, improving its specificity for bacterial etiologies. Serum levels elevate rapidly (within $\sim 4$ hours) and peak around 24-48 hours, making it an excellent early marker for infection [58]. Compared with CRP, it has been shown to be more sensitive and specific in identifying bacterial infections [59]. Also, unlike other infectious markers, its level is neither decreased (as is CRP) nor increased (as is white blood cell count) by the use of steroids [60]. An important drawback, however, is its lack of sensitivity for atypical infections such as Legionella, Mycoplasma, and Chlamydophilia [61].

First described as a biomarker for sepsis in 1993 [62], procalcitonin has since been validated repeatedly as not only a marker of bacterial infection, but also a correlate of severity in sepsis and septic shock [63]. A meta-analysis of 21 studies including over 6000 patients showed that an elevated procalcitonin level was a risk factor for mortality (RR 4.38) [64]. A review of 1770 patients with CAP showed that procalcitonin levels had an approximately linear association with the need for invasive respiratory or vasopressor support; at levels $>10 \mathrm{ng} / \mathrm{mL}$, the risk was $22.4 \%$ compared to $4 \%$ in patients with procalcitonin $<0.05 \mathrm{ng} / \mathrm{mL}$ [65].

Procalcitonin also serves as an important component of antimicrobial stewardship algorithms, helping to guide the decision to withhold antibiotics from low-risk patients and to abbreviate treatment courses in high-risk patients [66-68]. The latter is enabled by the progressive reduction in procalcitonin that accompanies successful treatment of infection; when its value drops to 80-90\% (depending on the study) antibiotics can be stopped. Although numerous reports have shown the efficacy of procalcitonin-guided prescribing strategies in decreasing antibiotic usage, questions have lingered regarding safety. To address these questions, Schuetz et al. conducted a comprehensive meta-analysis, including studies across a variety of clinical settings including primary care, emergency departments, and the ICU. The study not only confirmed dramatic reductions in antibiotic exposure and safety, but in fact showed that procalcitonin-guided strategies improve clinical outcomes in terms of mortality and treatment failure [69].

Conflicting data, however, have been presented. Most prominently, a study in 1656 patients randomized to procalcitonin-guided versus usual antibiotic care in the emergency department failed to demonstrate even a reduction in antibiotic exposure [70]. These differences may have arisen due to heightened awareness of proper antibiotic prescribing practices and/or the relatively low acuity of the patients in the trial. Further studies will be necessary to clarify these issues.

Overall, procalcitonin has clear potential to aid in the diagnosis and management of pneumonia, but, like any biomarker, it has important limitations. These include its elevation in renal failure and relative nonspecificity for acute inflamma- 
tion, including that related to cancer and tissue necrosis. Consequently, its usefulness will depend largely on the clinical setting (e.g., primary care vs. ICU) as well as the provider's knowledge of its biology and ability to integrate its significance within the larger clinical picture.

\section{Cytokines}

Inflammatory cytokines (IL-1, IL-6, IL-8, TNF $\alpha$, among others) are significantly higher in patients with severe pneumonia than in those with milder disease, and can predict mortality in hospitalized patients with CAP [71]. For example, a 27-component panel was followed in 247 patients, with IL-6, IL-8, and MIP-1 $\beta$ showing a strong association with disease severity and adverse short-term outcome [72]. The levels rise and fall rapidly though, on the order of hours, and are usually highest at presentation [73]. A study of 1886 patients with CAP demonstrated an elevation of cytokine levels in $82 \%$ of patients, but the overall response was heterogeneous and no pattern clearly identified severe sepsis [74]. Though scientifically sensical, the optimal implementation of these cytokine panels in clinical practice remains unclear.

\section{Newer Biomarkers}

An array of novel biomarkers for CAP are now emerging, including pro-atrial natriuretic peptide (pro-ANP), C-terminal pro-vasopressin (copeptin or pro-VNP), mid-regional pro-adrenomedullin (MR-proADM), and others. These have shown advantages compared to CRP and PCT but have not yet been introduced into widespread clinical practice.

Pro-ANP is elevated in lower respiratory tract infections during CAP [75], and has the potential to predict both 30-day and 180-day mortality [76]. A study of 549 patients with mild CAP showed that a single pro-ANP measurement was more accurate than CRP and PCT in predicting need for admission [77]. Exciting data from the CAPNETZ network indicate that pro-ANP and
pro-VNP are significantly higher in fatal CAP and possess superior AUCs to those of WBC, CURB-65, CRP, and procalcitonin [78].

Copeptin has been shown likewise to be higher in patients with pneumonia before antibiotic treatment [79]; it also has been shown in a study of pediatric CAP to be significantly higher in pneumonia cases and non-survivors [80].

MR-proADM has been shown to be predictive of complications and mortality in patients with CAP in a meta-analysis of eight studies with 4119 patients [81]. A systematic review of 12 studies similarly found that elevated MR-proADM was highly associated with an increase in short term mortality (OR 6.8) and complications (OR 5.0) [82].

Alveolar pentraxin 3 (PTX3), an acute-phase mediator produced by lung cells, represents another promising biomarker for pneumonia. An examination of 82 intubated patients' BAL fluid showed that elevated PTX3 levels were able to identify bacterial pneumonia [83]. A subsequent nested case-control study found that a $2.56 \mathrm{ng} /$ $\mathrm{mL}$ breakpoint had superb sensitivity and specificity for the diagnosis of VAP: $85 \%$ and $86 \%$, respectively [84]. Finally, kallistatin, an antiinflammatory kallikrein inhibitor, has been reported to be significantly consumed in severe CAP patients, and low levels early in admission are associated with increased mortality [85].

\section{Genetics}

It would be of great clinical value to have methods for predicting which patients will develop severe respiratory disease in response to a given pathogen and who will have milder courses, as at-risk patients can be given more prompt and aggressive care. A number of genetic analyses have been undertaken to address this need. Notable associations have been made with polymorphisms in pro-inflammatory factors such as TNF- $\alpha$, IL-6, and lymphotoxin alpha (LTA) [86]. Additionally, several single nucleotide polymorphisms (SNPs) in immune-related genes have been shown to confer either resistance or susceptibility to Streptococcal infection; for instance, mutations in the toll-interleukin 1 receptor 
domain-containing adaptor protein (TIRAP) and the NF-kappaB pathway have been identified as protective [87].

Rautanen and the ESICM/ECCRN group evaluated over 2500 patients and found 11 loci that correlated significantly with 28-day survival in ICU patients with severe CAP [88]. They further found a SNP in the FER gene to be highly correlated with survival; mortality was $9.5 \%$ in patients with the CC genotype, $15.2 \%$ in the TC genotype patients, and $25.3 \%$ in the TT genotype patients [88]. A follow-up study looked at the FER polymorphism status in 441 patients with ARDS in the ICU, and again found that the TT genotype patients had higher mortality, with a 90-day hazard ratio of 4.62 [89].

\section{Transcriptomics}

In the past decade, significant efforts have been made to identify gene expression signatures that accurately identify host response to infection. With the increasing availability of transcriptomic analysis, it may soon be feasible to obtain expression profiles in high-risk patients to aid in the diagnosis and management of pneumonia.

Several groups have assembled gene expression microarrays to diagnose acute infections, with the specific goal of distinguishing viral versus bacterial pneumonia [90, 91]. In 2007, Ramilo and colleagues examined 131 peripheral blood samples and characterized 35 genes able to discriminate bacterial versus viral pneumonia with $95 \%$ accuracy [92]. Suarez et al. analyzed whole blood transcriptional data from 118 patients with lower respiratory tract infections and identified 3376 genes associated with bacterial infection and 2391 with viral infections. Using the K-nearest neighbors' algorithm, they identified a parsimonious ten-gene classifier that could distinguish between the two with $95 \%$ sensitivity and $92 \%$ specificity, greatly outperforming procalcitonin [93]. Scicluna's team looked at blood microarray analysis of critically ill patients with and without CAP and defined a 78-gene signature for CAP [94]. They narrowed this down to a ratio of the FAIM3 (fas apoptotic inhibitory molecule 3) and PLAC8 (placenta specific 8) gene expression, leading to area under curve of 0.845, again outperforming procalcitonin [94].

Sweeney and Khatri have derived a set of seven genes that discriminate bacterial versus viral infections, which they validated in 30 independent cohorts [95]. Tsalik and his group looked at peripheral whole blood gene expression in 273 subjects with community onset respiratory infections, and used sparse logistic regression to develop classifiers for bacterial infections (71 probes) versus viral infections (33 probes) and noninfectious causes (26 probes); the overall accuracy was higher than that of procalcitonin and also three other published classifiers of bacterial versus viral infections [96].

While the foregoing studies require the use of multi-gene assays, Tang and colleagues recently used genomic analysis of 1071 patients to find a single gene capable of identifying viral infection, interferon alpha inducible protein 27 (IFI27) [97]. They demonstrated a considerable upregulation at the transcript level in patients with influenza as opposed to bacterial pneumonia, likely due to the specific activation of interferon signaling pathways downstream of pathogen recognition receptors selective for virus.

With regards to predicting host response to lung infections, there have been a number of recent advances. Meijas et al. looked at a cohort of infants hospitalized with RSV, HRV, and influenza and identified a score calculated from RSV transcriptional profiles that correlated with outcomes including length of hospitalization, duration of supplementation oxygen, and clinical disease severity score-an important example of the potential utility of transcriptomics in predicting the need for intensive care [98]. Banchereau et al. characterized whole blood transcriptional profiles of patients hospitalized with community-acquired Staphylococcus aureus infection and were able to generate a score they called molecular distance to health (MDTH), which correlated with elevated inflammatory markers, longer duration of hospitalization, and more severe disease [99].

A transcriptomic analysis of peripheral leukocytes from 265 ICU patients with sepsis from CAP found two distinct sepsis response signa- 
tures "SRS", which they categorized as "SRS1" and "SRS2". Over 3000 genes were noted to be differentially expressed between the groups, with 2260 downregulated in the SRS1 group. SRS1, which had lower expression of Toll-like receptor (TLR) signals, downregulation of human leukocyte antigen (HLA) class II genes, and decreased T-cell activation, was associated with a higher 14-day mortality than SRS2. They distilled out a set of just seven genes to classify patients into SRS1 or SRS2 [100]. Schaack et al. drew from over 900 microarray samples from public repositories from patients with sepsis and identified two clusters of patients according to global blood transcriptomes; these clusters exhibited expression of genes demonstrating a loss of monocyte and T-cell function, indicating a group of patients with higher immunosuppression that may need more aggressive care [101].

\section{Metabolomics and Lipidomics}

Metabolomics is an emerging area of investigation aimed at characterizing the cellular metabolic changes during infection [102]. Groups have found metabolic patterns specific to sepsis, some metabolites that potentially can identify severe versus less severe pneumonia, and certain metabolites that may predict poorer outcomes. For instance, To's group found that 13 lipid metabolites could discriminate between CAP and non-CAP cases with an AUC of $>0.8$, and that trihexosylceramide levels were higher in fatal cases [103]. A separate group used 1D 1H nuclear magnetic resonance (NMR) spectra to generate metabolic profiles from 15 patients with pneumonia; comparing the metabolic profiles using Orthogonal Partial Least Squares Discriminant Analysis (OPLS-DA) they were able to differentiate cases of VAP from those without [104]. Finally, Ning et al. analyzed 119 patients with CAP and found markedly different metabolic patterns as assessed by liquid chromatographymass spectrometry (LC-MS) compared with control patients [105]. Sphinganine, p-Cresol sulfate, and DHEA-S were significantly lower, and in combination with lactate, this panel could dis- criminate severe CAP from non-severe CAP with an impressive AUC of 0.911 , better than the CURB-65, PSI, and APACHE II scores [105].

\section{Sputum, Bronchoalveolar Lavage, and Exhaled Breath Sampling}

Numerous studies have shown that the location of specimen sampling importantly influences diagnostic yield. While the most common tests are those tested in the serum, sputum and airway fluid (BAL, non-bronchoscopic BAL, tracheal aspirates) should also be evaluated. A study of BAL fluid from 47 patients found that median WBC count and neutrophil percentages were significantly higher in bacterial than viral pneumonia. Furthermore, BAL WBC count was an independent predictor of bacterial pneumonia, and when combined with procalcitonin or CRP, the composite reached a sensitivity of $95.8 \%$ and a specificity of $95.7 \%$ [106]. Importantly, the utility of BAL leukocytosis extends to immunocompromised patients as well, as demonstrated by a study of 107 patients with either hematological malignancy or solid organ transplant. This showed that BAL fluid neutrophil percentage had the highest AUC to predict bacterial infection; in contrast, neither the presence of infiltrates nor leukocyte count was helpful in diagnosing bacterial infection [107].

Interestingly, a discordant inflammatory response has been demonstrated in blood versus sputum in patients with severe CAP. Neutrophil respiratory burst was increased as expected in the blood, but significantly diminished in the lung, indicating either a local failure of inflammatory response or possibly an adaptive immunosuppression to protect lung tissue from immunopathology [108].

As discussed above, breathomics, or measurement of (VOCs) in exhaled breath, is a noninvasive means of sampling host metabolites. Promising early studies have shown discernable metabolomic changes in pneumonia due inflammation and oxidative stress [109]; further work will be necessary to understand the potential clinical utility of such methods. 


\section{Future Application of Technologies}

Genomics, Transcriptomics

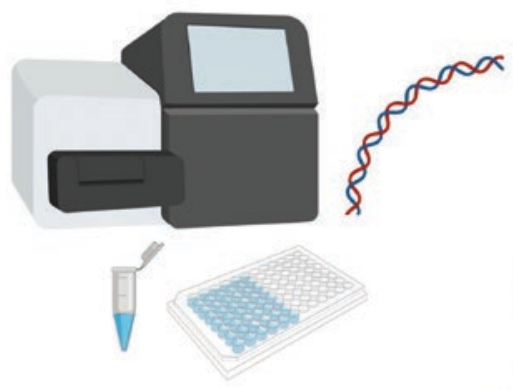

\section{Proteomics}

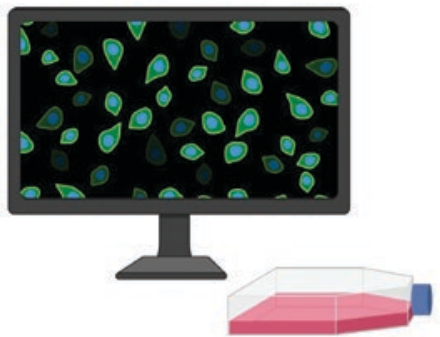

Fig. 12.2 Future application of technologies for the diagnosis and management of pneumonia. This approach may include whole genome sequencing, transcriptomics, pro- teomics, mass spectrometry, and other methods with the goal of improving precision in the treatment of patients with pneumonia

\section{Conclusions}

With ongoing advances in molecular and biochemical methods, we aim for an ever-greater level of diagnostic detail, with the ultimate goal of reliably diagnosing causative pathogens in pneumonia, as well as predicting decompensations, complications, and resolution. In addition to traditional clinical evaluation, we now employ powerful diagnostic tools to evaluate both host and pathogen including biomarkers and PCR; the advent of technologies such as mass spectroscopy and WGS promises further improvements in diagnostic clarity. In addition, the impressive (but potentially overwhelming) amount of data available through electronic medical records and multi-omics modalities including sequencing data may necessitate machine learning algo-

\section{Mass spectrometry}

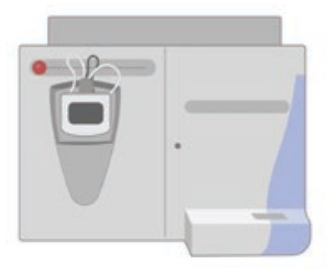

Machine Learning

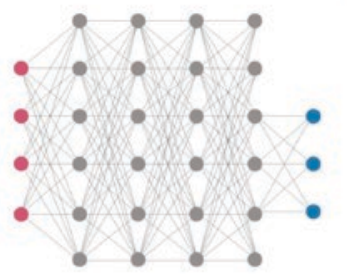

rithms to further optimize pneumonia diagnosis and management.

Incorporating these techniques, we can reenvision the case presented at the outset of this chapter (see Fig. 12.2). The same 45-year-old patient presents with fever and cough. WGS is performed on a sputum sample and reveals influenza B infection with no bacterial superinfection. Antibiotics are withheld, and he initially improves on neuraminidase inhibitor therapy. However, 5 days later he has recurring fevers and worsening hypoxia. Analysis of his exhaled volatile compounds reveals a profile consistent with $S$. aureus pneumonia; mass spectrometry analysis of a sputum sample rapidly confirms $S$. aureus infection and further identifies mecA, indicating MRSA. Vancomycin is promptly added, and the team considers transferring him to a higher level 

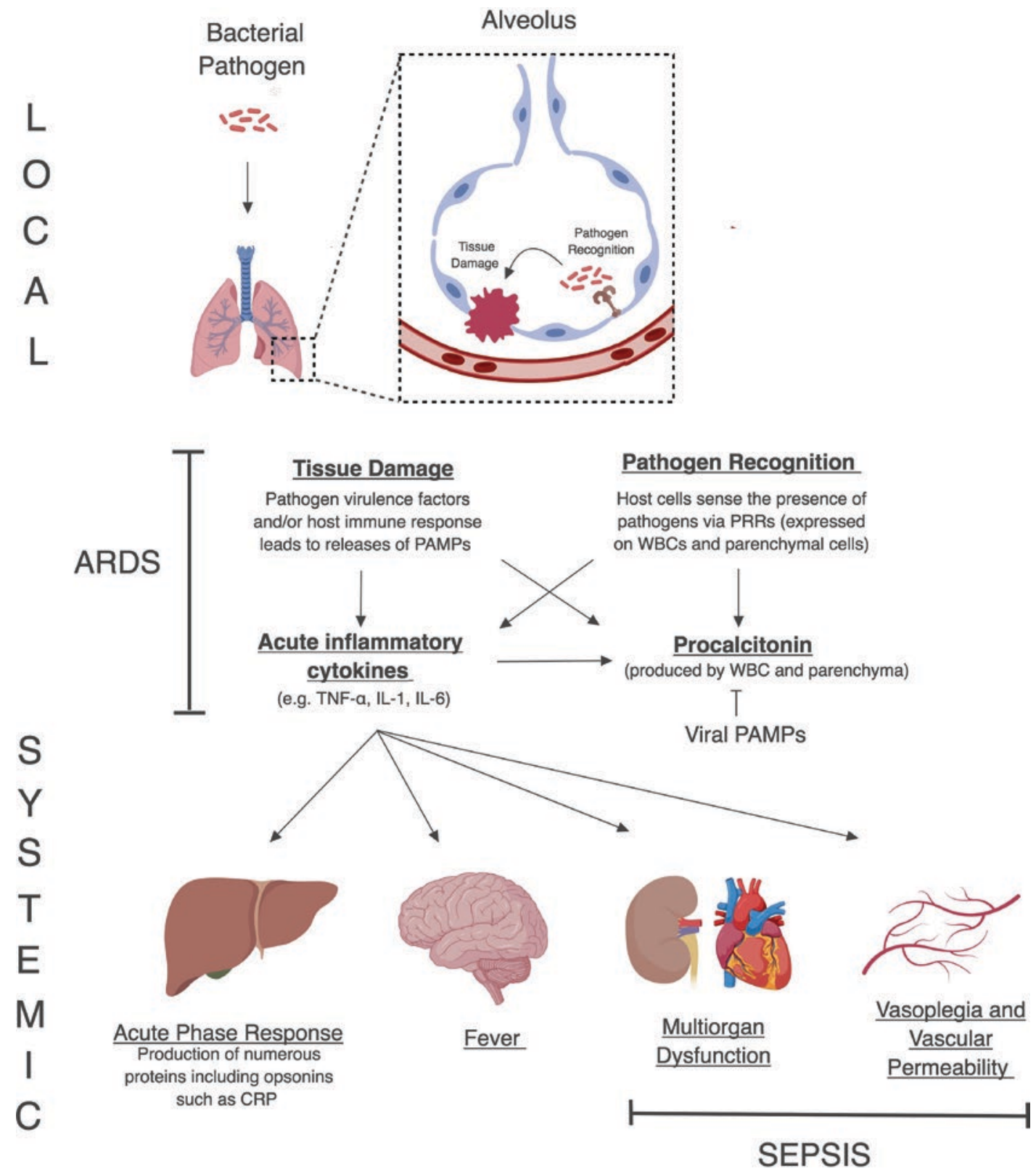

Fig. 12.3 A summary of local and systemic responses to lung infection. Using bacterial pneumonia as an example, pathogens access alveoli and trigger immune responses through the elaboration of pathogen associated molecular patterns (PAMPs), which activate pathogen recognition receptors (PRRs) and production of inflammatory cytokines. Pathogens also damage lung tissue directly, in some cases leading to acute respiratory distress syndrome (ARDS). In general, procalcitonin is secreted during bacterial and not viral infections. Bacterial lung infections can also result in systemic inflammation characterized by acute phase response and production of C-reactive protein (CRP), fever, multiorgan failure, vasoplegia, and vascular permeability that presents as sepsis 
of care for closer monitoring. However, his proANP and MR-pro-ADM are not elevated, and onsite transcriptomic analysis of peripheral leukocytes does not show an SRS1 pattern, reassuring the team that he is not a high risk for decompensating. He is safely sent to the general medicine floor, continues to improve, and is discharged home after his short hospitalization.

Several obstacles stand in the way of realizing this level of diagnostic precision and therapeutic sophistication, however. For instance, the costs associated with many of these tests are prohibitive, especially in smaller medical centers. Therefore, technological improvements will be necessary to decrease operating costs while clinical studies must be performed to identify those patients best suited for such advanced and more expensive diagnostics. Basic and translational studies are also needed to more fully elucidate the pathophysiology and natural history of pneumonia to inform future clinical studies and further explain existing data. Ultimately, a multidisciplinary approach involving clinical research, basic biology, chemical analysis, assay optimization, and computational science are needed to usher in an era where the potentially transformative technologies described above are used routinely in the diagnosis and management of pneumonia.

\section{Key Point Summary (see Fig. 12.3)}

- Traditional methods for the diagnosis and characterization of pulmonary infections are inadequate.

- The use of advanced molecular diagnostics such as newer biomarkers, multiplex PCR, mass spectrometry, metagenomics, and metataxonomics can improve clinical precision in the diagnosis of pneumonia.

- More studies involving biomarkers and multi-omics approaches are needed to help better characterize the host response to pulmonary infections.
- Incorporation of advanced tools for diagnostics and host response measurements will likely enable personalization of our management of pneumonia and improve outcomes.

\section{References}

1. Ferkol T, Schraufnagel D. The global burden of respiratory disease. Ann Am Thorac Soc. 2014;11(3):404-6.

2. Albaum MN, Hill LC, Murphy M, Li YH, Fuhrman CR, Britton CA, Kapoor WN, Fine MJ. Interobserver reliability of the chest radiograph in community-acquired pneumonia. PORT Investigators. Chest. 1996;110(2):343-50.

3. Kraus EM, et al. Antibiotic prescribing for acute lower respiratory tract infections (LRTI) - guideline adherence in the German primary care setting: an analysis of routine data. PLoS One. 2017;12(3):e0174584.

4. Mandell LA, et al. Infectious Diseases Society of America/American Thoracic Society consensus guidelines on the management of community-acquired pneumonia in adults. Clin Infect Dis. 2007;44(Suppl 2):S27-72.

5. Metlay JP. Does this patient have community-acquired pneumonia? Diagnosing pneumonia by history and physical examination. JAMA. 1997;278(17):1440-5.

6. Jain S, et al. Community-acquired pneumonia requiring hospitalization among U.S. adults. N Engl J Med. 2015;373(5):415-27.

7. Waters B, Muscedere J. A 2015 update on ventilatorassociated pneumonia: new insights on its prevention, diagnosis, and treatment. Curr Infect Dis Rep. 2015;17(8):496.

8. Dixon P, et al. A systematic review of matrix-assisted laser desorption/ionisation time-of-flight mass spectrometry compared to routine microbiological methods for the time taken to identify microbial organisms from positive blood cultures. Eur J Clin Microbiol Infect Dis. 2015;34(5):863-76.

9. Self WH, et al. High discordance of chest x-ray and computed tomography for detection of pulmonary opacities in ED patients: implications for diagnosing pneumonia. Am J Emerg Med. 2013;31(2):401-5.

10. Basi SK, et al. Patients admitted to hospital with suspected pneumonia and normal chest radiographs: epidemiology, microbiology, and outcomes. Am J Med. 2004;117(5):305-11.

11. Andreo F, et al. Impact of rapid urine antigen tests to determine the etiology of community-acquired pneumonia in adults. Respir Med. 2006;100(5):884-91.

12. Sordé R, et al. Current and potential usefulness of pneumococcal urinary antigen detection in hospital- 
ized patients with community-acquired pneumonia to guide antimicrobial therapy. Arch Intern Med. 2011;171(2):166-72.

13. Harris AM, et al. Influence of Antibiotics on the Detection of Bacteria by Culture-Based and CultureIndependent Diagnostic Tests in Patients Hospitalized With Community-Acquired Pneumonia. Open Forum Infect Dis. 2017;4(1):ofx014.

14. Dionne M, Hatchette T, Forward K. Clinical utility of a Legionella pneumophila urinary antigen test in a large university teaching hospital. Can J Infect Dis. 2003;14(2):85-8.

15. Poritz MA, et al. FilmArray, an automated nested multiplex PCR system for multi-pathogen detection: development and application to respiratory tract infection. PLoS One. 2011;6(10):e26047.

16. Jartti $\mathrm{T}$, et al. Identification of respiratory viruses in asymptomatic subjects: asymptomatic respiratory viral infections. Pediatr Infect Dis J. 2008;27(12):1103-7.

17. Rello J, et al. Severity of pneumococcal pneumonia associated with genomic bacterial load. Chest. 2009;136(3):832-40.

18. Werno AM, Anderson TP, Murdoch DR. Association between pneumococcal load and disease severity in adults with pneumonia. J Med Microbiol. 2012;61(Pt 8):1129-35.

19. Patel PA, et al. Evaluation of multiple real-time PCR tests on nasal samples in a large MRSA surveillance program. Am J Clin Pathol. 2015;143(5):652-8.

20. Peacock SJ, Paterson GK. Mechanisms of methicillin resistance in Staphylococcus aureus. Annu Rev Biochem. 2015;84:577-601.

21. Carroll KC. Rapid diagnostics for methicillinresistant Staphylococcus aureus. Mol Diagn Ther. 2008;12(1):15-24.

22. Kais M, et al. Quantitative detection of Streptococcus pneumoniae, Haemophilus influenzae, and Moraxella catarrhalis in lower respiratory tract samples by real-time PCR. Diagn Microbiol Infect Dis. 2006;55(3):169-78.

23. Abdeldaim G, et al. Is quantitative PCR for the pneumolysin (ply) gene useful for detection of pneumococcal lower respiratory tract infection? Clin Microbiol Infect. 2009;15(6):565-70.

24. Steingart KR, et al. Sputum processing methods to improve the sensitivity of smear microscopy for tuberculosis: a systematic review. Lancet Infect Dis. 2006;6(10):664-74.

25. Diagnostic Standards and Classification of Tuberculosis in Adults and Children. This official statement of the American Thoracic Society and the Centers for Disease Control and Prevention was adopted by the ATS Board of Directors, July 1999. This statement was endorsed by the Council of the Infectious Disease Society of America, September 1999. Am J Respir Crit Care Med. 2000;161(4 Pt 1):1376-95.

26. Marks SM, et al. The health-system benefits and costeffectiveness of using Mycobacterium tuberculosis direct nucleic acid amplification testing to diagnose tuberculosis disease in the United States. Clin Infect Dis. 2013;57(4):532-42.
27. Lim TK, et al. Role of clinical judgment in the application of a nucleic acid amplification test for the rapid diagnosis of pulmonary tuberculosis. Chest. 2003;124(3):902-8.

28. Conaty SJ, et al. The interpretation of nucleic acid amplification tests for tuberculosis: do rapid tests change treatment decisions? J Infect. 2005;50(3):187-92.

29. Catanzaro A, et al. The role of clinical suspicion in evaluating a new diagnostic test for active tuberculosis: results of a multicenter prospective trial. JAMA. 2000;283(5):639-45.

30. Centers for Disease Control and Prevention (CDC). Updated guidelines for the use of nucleic acid amplification tests in the diagnosis of tuberculosis. JAMA. 2009;301(10):1014.

31. Centers for Disease, C. and Prevention. Availability of an assay for detecting Mycobacterium tuberculosis, including rifampin-resistant strains, and considerations for its use - United States, 2013. MMWR Morb Mortal Wkly Rep. 2013;62(41):821-7.

32. Vrioni G, et al. MALDI-TOF mass spectrometry technology for detecting biomarkers of antimicrobial resistance: current achievements and future perspectives. Ann Transl Med. 2018;6(12):240.

33. Angeletti S. Matrix assisted laser desorption time of flight mass spectrometry (MALDI-TOF MS) in clinical microbiology. J Microbiol Methods. 2017;138:20-9.

34. Jung JS, et al. Rapid detection of antibiotic resistance based on mass spectrometry and stable isotopes. Eur J Clin Microbiol Infect Dis. 2014;33(6):949-55.

35. van Oort PM, et al. The potential role of exhaled breath analysis in the diagnostic process of pneumonia-a systematic review. J Breath Res. 2018;12(2):024001.

36. Schnabel R, et al. Analysis of volatile organic compounds in exhaled breath to diagnose ventilatorassociated pneumonia. Sci Rep. 2015;5:17179.

37. Toma I, et al. Single-molecule long-read $16 \mathrm{~S}$ sequencing to characterize the lung microbiome from mechanically ventilated patients with suspected pneumonia. J Clin Microbiol. 2014;52(11):3913-21.

38. Conway Morris A, et al. $16 \mathrm{~S}$ pan-bacterial PCR can accurately identify patients with ventilator-associated pneumonia. Thorax. 2017;72(11):1046-8.

39. Dupont $\mathrm{H}$, et al. Impact of appropriateness of initial antibiotic therapy on the outcome of ventilatorassociated pneumonia. Intensive Care Med. 2001;27(2):355-62.

40. Deng X, et al. Whole-genome sequencing for surveillance of invasive pneumococcal diseases in Ontario, Canada: rapid prediction of genotype, antibiotic resistance and characterization of emerging serotype 22F. Front Microbiol. 2016;7:2099.

41. Ellington MJ, et al. The role of whole genome sequencing in antimicrobial susceptibility testing of bacteria: report from the EUCAST Subcommittee. Clin Microbiol Infect. 2017;23(1):2-22.

42. Ocheretina $\mathrm{O}$, et al. False-positive rifampin resistant results with Xpert MTB/RIF version 4 assay in clinical samples with a low bacterial load. Diagn Microbiol Infect Dis. 2016;85(1):53-5. 
43. Doyle RM, et al. Direct whole-genome sequencing of sputum accurately identifies drug-resistant mycobacterium tuberculosis faster than MGIT culture sequencing. J Clin Microbiol. 2018;56(8):e00666-18.

44. Votintseva AA, et al. Same-day diagnostic and surveillance data for tuberculosis via whole-genome sequencing of direct respiratory samples. J Clin Microbiol. 2017;55(5):1285-98.

45. Cohen T, et al. Mixed-strain mycobacterium tuberculosis infections and the implications for tuberculosis treatment and control. Clin Microbiol Rev. 2012;25(4):708-19.

46. Qiu S, et al. Whole-genome sequencing for tracing the transmission link between two ARD outbreaks caused by a novel HAdV serotype 7 variant, China. Sci Rep. 2015;5(1):13617.

47. Molyneaux PL, et al. Outgrowth of the bacterial airway microbiome after rhinovirus exacerbation of chronic obstructive pulmonary disease. Am J Respir Crit Care Med. 2013;188(10):1224-31.

48. Coll F, et al. Genome-wide analysis of multi- and extensively drug-resistant Mycobacterium tuberculosis. Nat Genet. 2018;50(2):307-16.

49. Li Y, et al. Validation of $\beta$-lactam minimum inhibitory concentration predictions for pneumococcal isolates with newly encountered penicillin binding protein (PBP) sequences. BMC Genomics. 2017;18(1):621.

50. Nguyen M, et al. Developing an in silico minimum inhibitory concentration panel test for Klebsiella pneumoniae. Sci Rep. 2018;8(1):421.

51. Abernethy TJ, Avery OT. The occurrence during acute infections of a protein not normally present in the blood : i. Distribution of the reactive protein in patients' sera and the effect of calcium on the flocculation reaction with c polysaccharide of pneumococcus. J Exp Med. 1941;73(2):173-82.

52. Tillett WS, Francis T. Serological reactions in pneumonia with a non-protein somatic fraction of pneumococcus. J Exp Med. 1930;52(4):561-71.

53. García Vázquez E, et al. C-reactive protein levels in community-acquired pneumonia. Eur Respir J. 2003;21(4):702-5

54. Aabenhus R, et al. Biomarkers as point-of-care tests to guide prescription of antibiotics in patients with acute respiratory infections in primary care. Cochrane Database Syst Rev. 2014;11:CD010130.

55. Hohenthal U, et al. Utility of C-reactive protein in assessing the disease severity and complications of community-acquired pneumonia. Clin Microbiol Infect. 2009;15(11):1026-32.

56. Méndez R, et al. Initial inflammatory profile in community-acquired pneumonia depends on time since onset of symptoms. Am J Respir Crit Care Med. 2018;198(3):370-8.

57. Müller B, et al. Ubiquitous expression of the calcitonin-I gene in multiple tissues in response to Sepsis 1. J Clin Endocrinol Metab. 2001;86(1):396-404.

58. Meisner M. Update on procalcitonin measurements. Ann Lab Med. 2014;34(4):263-73.

59. Lee H. Procalcitonin as a biomarker of infectious diseases. Korean J Intern Med. 2013;28(3):285-91.
60. Reinhart K, et al. New approaches to sepsis: molecular diagnostics and biomarkers. Clin Microbiol Rev. 2012;25(4):609-34.

61. Jereb M, Kotar T. Usefulness of procalcitonin to differentiate typical from atypical communityacquired pneumonia. Wien Klin Wochenschr. 2006;118(5-6):170-4.

62. Assicot M, et al. High serum procalcitonin concentrations in patients with sepsis and infection. Lancet. 1993;341(8844):515-8.

63. Reinhart K, Meisner M. Biomarkers in the critically ill patient: procalcitonin. Crit Care Clin. 2011;27(2):253-63.

64. Liu D, et al. Prognostic value of procalcitonin in pneumonia: a systematic review and meta-analysis. Respirology. 2016;21(2):280-8.

65. Self WH, et al. Procalcitonin as an early marker of the need for invasive respiratory or vasopressor support in adults with community-acquired pneumonia. Chest. 2016;150(4):819-28.

66. $\mathrm{Li} \mathrm{H}$, et al. Meta-analysis and systematic review of procalcitonin-guided therapy in respiratory tract infections. Antimicrob Agents Chemother. 2011;55(12):5900-6.

67. Mueller B. Procalcitonin-guided antibiotic therapy and hospitalisation in patients with lower respiratory tract infections: the prohosp study. http://isrctn.org/, 2012.

68. Bouadma L, et al. Use of procalcitonin to reduce patients' exposure to antibiotics in intensive care units (PRORATA trial): a multicentre randomised controlled trial. Lancet. 2010;375(9713):463-74.

69. Schuetz P, et al. Effect of procalcitonin-guided antibiotic treatment on mortality in acute respiratory infections: a patient level meta-analysis. Lancet Infect Dis. 2018;18(1):95-107.

70. Huang DT, et al. Procalcitonin-guided use of antibiotics for lower respiratory tract infection. N Engl J Med. 2018;379(3):236-49.

71. Menendez R, et al. Biomarkers improve mortality prediction by prognostic scales in community-acquired pneumonia. Thorax. 2009;64(7):587-91.

72. Siljan WW, et al. Cytokine responses, microbial aetiology and short-term outcome in communityacquired pneumonia. Eur $\mathrm{J}$ Clin Investig. 2018;48(1):e12865.

73. Endeman H, et al. Systemic cytokine response in patients with community-acquired pneumonia. Eur Respir J. 2011;37(6):1431-8.

74. Kellum JA, et al. Understanding the inflammatory cytokine response in pneumonia and sepsis: results of the Genetic and Inflammatory Markers of Sepsis (GenIMS) Study. Arch Intern Med. 2007;167(15):1655-63.

75. Müller B, et al. Circulating levels of pro-atrial natriuretic peptide in lower respiratory tract infections. $\mathrm{J}$ Intern Med. 2006;260(6):568-76.

76. Vazquez M, et al. MR-pro-atrial natriuretic peptide (MR-proANP) predicts short- and long-term outcomes in respiratory tract infections: a prospective validation study. Int J Cardiol. 2012;156(1):16-23.

77. Claessens Y-E, et al. Accuracy of C-reactive protein, procalcitonin, and mid-regional pro-atrial natriuretic 
peptide to guide site of care of community-acquired pneumonia. Intensive Care Med. 2010;36(5):799-809.

78. Welte T, Suttorp N, Marre R. CAPNETZ-communityacquired pneumonia competence network. Infection. 2004;32(4):234.

79. Krüger S, et al. C-terminal provasopressin (copeptin) in patients with community-acquired pneumoniainfluence of antibiotic pre-treatment: results from the German competence network CAPNETZ. J Antimicrob Chemother. 2009;64(1):159-62.

80. Mohamed GB, et al. Predictive value of copeptin as a severity marker of community-acquired pneumonia. Electron Physician. 2017;9(7):4880-5.

81. Liu D, et al. Prognostic value of mid-regional proadrenomedullin (MR-proADM) in patients with community-acquired pneumonia: a systematic review and meta-analysis. BMC Infect Dis. 2016;16(1):232.

82. Cavallazzi R, et al. Midregional proadrenomedullin for prognosis in community-acquired pneumonia: a systematic review. Respir Med. 2014;108(11): 1569-80.

83. Mauri T, et al. Alveolar pentraxin 3 as an early marker of microbiologically confirmed pneumonia: a threshold-finding prospective observational study. Crit Care. 2014;18(5):562.

84. Bilgin H, et al. Sequential Measurements of Pentraxin 3 Serum Levels in Patients with Ventilator-Associated Pneumonia: A Nested Case-Control Study. Can J Infect Dis Med Microbiol. 2018;2018:4074169.

85. Lin W-C, et al. Plasma kallistatin levels in patients with severe community-acquired pneumonia. Crit Care. 2013;17(1):R27.

86. Chung LP, Waterer GW. Genetic predisposition to respiratory infection and sepsis. Crit Rev Clin Lab Sci. 2011;48(5-6):250-68.

87. Khor CC, et al. A Mal functional variant is associated with protection against invasive pneumococcal disease, bacteremia, malaria and tuberculosis. Nat Genet. 2007;39(4):523-8.

88. Rautanen A, et al. Genome-wide association study of survival from sepsis due to pneumonia: an observational cohort study. Lancet Respir Med. 2015;3(1):53-60.

89. Hinz J, et al. The FER rs4957796 TT genotype is associated with unfavorable 90-day survival in Caucasian patients with severe ARDS due to pneumonia. Sci Rep. 2017;7(1):9887.

90. Graf $\mathrm{EH}$, et al. Unbiased detection of respiratory viruses by use of RNA sequencing-based metagenomics: a systematic comparison to a commercial PCR panel. J Clin Microbiol. 2016;54(4):1000-7.

91. Schlaberg R, et al. Viral pathogen detection by metagenomics and pan-viral group polymerase chain reaction in children with pneumonia lacking identifiable etiology. J Infect Dis. 2017;215(9):1407-15.

92. Ramilo O, et al. Gene expression patterns in blood leukocytes discriminate patients with acute infections. Blood. 2007;109(5):2066-77.

93. Suarez NM, et al. Superiority of transcriptional profiling over procalcitonin for distinguishing bacterial from viral lower respiratory tract infections in hospitalized adults. J Infect Dis. 2015;212(2):213-22.

94. Scicluna BP, et al. A molecular biomarker to diagnose community-acquired pneumonia on intensive care unit admission. Am J Respir Crit Care Med. 2015;192(7):826-35.

95. Sweeney TE, Wong HR, Khatri P. Robust classification of bacterial and viral infections via integrated host gene expression diagnostics. Sci Transl Med. 2016;8(346):346ra91.

96. Tsalik EL, et al. Host gene expression classifiers diagnose acute respiratory illness etiology. Sci Transl Med. 2016;8(322):322ra11.

97. Tang BM, et al. A novel immune biomarker discriminates between influenza and bacteria in patients with suspected respiratory infection. Eur Respir J. 2017;49(6):1602098.

98. Mejias A, et al. Whole blood gene expression profiles to assess pathogenesis and disease severity in infants with respiratory syncytial virus infection. PLoS Med. 2013;10(11):e1001549.

99. Banchereau R, et al. Host immune transcriptional profiles reflect the variability in clinical disease manifestations in patients with Staphylococcus aureus infections. PLoS One. 2012;7(4):e34390.

100. Davenport EE, et al. Genomic landscape of the individual host response and outcomes in sepsis: a prospective cohort study. Lancet Respir Med. 2016;4(4):259-71.

101. Schaack D, et al. The immunosuppressive face of sepsis early on intensive care unit-a large-scale microarray meta-analysis. PLoS One. 2018;13(6):e0198555.

102. Leoni D, Rello J. Severe community-acquired pneumonia: optimal management. Curr Opin Infect Dis. 2017;30(2):240-7.

103. To KK, et al. Lipid metabolites as potential diagnostic and prognostic biomarkers for acute community acquired pneumonia. Diagn Microbiol Infect Dis. 2016;85(2):249-54.

104. Antcliffe D, et al. Metabolic profiling in patients with pneumonia on intensive care. EBioMedicine. 2017;18:244-53.

105. Ning P, et al. Metabolic profiles in communityacquired pneumonia: developing assessment tools for disease severity. Crit Care. 2018;22(1):130.

106. Choi S-H, et al. Usefulness of cellular analysis of bronchoalveolar lavage fluid for predicting the etiology of pneumonia in critically ill patients. PLoS One. 2014;9(5):e97346.

107. Stolz D, et al. BAL neutrophils, serum procalcitonin, and C-reactive protein to predict bacterial infection in the immunocompromised host. Chest. 2007;132(2):504-14.

108. Fernandez-Botran R, et al. Contrasting inflammatory responses in severe and non-severe community-acquired pneumonia. Inflammation. 2014;37(4):1158-66.

109. Boots AW, et al. The versatile use of exhaled volatile organic compounds in human health and disease. J Breath Res. 2012;6(2):027108. 